\title{
Eksplorasi Konsep Falah Perspektif Umer Chapra
}

\author{
Syamsuri $^{1}$, Nurul Rahmania ${ }^{2}$, Ardiyanti $^{3}$ \\ ${ }^{1,2}$ Hukum Ekonomi Syari'ah, Ekonomi Islam, University of Darussalam Gontor, \\ Mantingan-Ngawi, East Java 63261, Indonesia \\ ${ }^{3}$ Pendidikan Bahasa Arab, Tarbiyah, University of Darussalam Gontor, \\ Mantingan-Ngawi, East Java 63261, Indonesia \\ Email: 1'syamsuri@unida.gontor.ac.id, 2nurulrohmania137@gmail.com \\ ${ }^{3}$ ardiyantiardiyanti42005@mhs.unida.gontor.ac.id
}

\begin{abstract}
The main focus of this research is to discuss the concept of M. Umer Chapra's thought in the world of economics. This study uses a qualitative-descriptive approach with library research techniques (Library Research). The results of the study show that $M$. Umer Chapra's thoughts in the field of economics have formulated many religious, traditional to modern sciences. Among the many concepts of thought, the concepts of falah, hayyah thayyibah, and economic obstacles for Muslims are still interesting discussions to be studied. From his theory of economic thought, Umer Chapra puts forward moral intensity as the most important thing to be taken into account. Because morality is the key to the life goals of falah and hayyah thayyibah. As well as being able to deliver a fair Islamic economy in the socio-economic field, so that it becomes a means of solving the failure of the Socialist and Capitalist economies.
\end{abstract}

Keywords: The concept of Falah and Hayah Thoyyibah, A prosperous country

\begin{abstract}
Abstrak
Fokus utama dalam penelitian adalah membahas konsep pemikiran M. Umer Chapra dalam dunia ekonomi. Penelitian ini menggunakan metode pendekatan KualitatifDeskriptif dengan teknik riset kepustakaan (Library Research). Hasil penelitian menunjukkan Pemikiran M. Umer Chapra dalam bidang ekonomi yang telah banyak memformulasikan antara ilmu agama, tradisional hingga modern. Di antara banyaknya konsep pemkiriannya, konsep falah, hayyah thayyibah dan rintangan ekonomi para umat Islam menjadi pembahasan yang masih menarik untuk dikaji. Dari teori pemikiran ekonominya pun Umer Chapra sangat mengedepankan intensitas moral menjadi hal terpenting untuk diperhitungkan. Sebab moralitas merupakan kunci dari tujuan kehidupan falah dan hayyah thayyibah. Serta mampu menghantarkan perekonomian Islam yang adil dalam bidang sosio-ekonomi, sehingga menjadi sarana solusi dari kegagalan kaum ekonomi Sosialis dan Kapitalis.
\end{abstract}

Kata Kunci: Konsep Falah dan Hayah Thoyyibah, Negara Sejahtera

\section{PENDAHULUAN}

Wujud puncak dari rangkaian aktivitas ekonomi Islam adalah terealisasikannya hajat dari maqahid syariah itu sendiri. Dimana hasil dari tujuan maqashid syariah 
adalah tercapainya kesejahteraan dan kebahagiaan dunia maupun akhirat yang merupakan refleksi dari kapatuhan manusia yang baik dan mulia (hayyah thayyibah). Pada hakikatnya, arah dari tujuan peradaban manusia adalah meraih kesejahteraan hidup, walaupun makna kesejahteraan itu sendiri masih menjadi suatu problematika yang belum ditemukan titik terangnya, namun, makna sejahterah masih mendominasi kearah terpenuhinya kesejahteraan terhadap pemenuhan meterial dunia semata.

Ajaran Islam selalu menempatkan Al-Quran dan Sunnah sebagai pondasi dari kehidupan manusia. Sebab, dengan berbagai macam dinamika permasalahan hidup, manusia selalu dituntun untuk tetap kukuh berpegang pada aqidah dengan melihat segala akitivitas hanya untuk ibadah, taat hukum syariah sebagai prosedur dari manusia yang berakhlak, serta kerangka dan konsep yang bersangkut paut kepada sebuah keadilan dan kebajikan. Oleh sebab itu, datangnya ekonomi Islam dipandang sebagai ekonomi yang alternatif, sebab solusi yang disajikan mampu menyelaraskan segala aspek dalam kehidupan manusia, dan solusi pemecahan dari problem ekonomi konvensional. Ekonomi Islam hadir dengan menyajikan konsep falah yang mengarahkan pemahaman manusia kepada hakikat dari manusia itu sendiri. Konsep falah merupakan pencapaian yang fundamental dari aktivitas manusia, dengan tercapainya kebahagian dari sudut material dan spiritual hingga berhasil meraih kesejahteraan dunia maupun akhirat.

Penanaman faham falah berasal dari campur tangan dan pemikiran ekonom Islam yaitu M. Umer Chapra. Banyak dari hasil pemikiran beliau menegaskan bahwa kesejateraah bukan hanya refleksi dari terpenuhinya materi. Melainkan tidak keluar dari dasar moral yang nantinya akan tersalurkan kepada distribusi yang berimbang, tidak berada pada satu pihak tertentu saja, namun menyeluruh dengan proposinya masingmasing. Akan tetapi, tidak sedikit dari pemikir ekonom Islam yang tidak setuju dengan pemikiran Umer Chapra ini. Sebab sebagian dari mereka masih mengarah kepada pemikiran ekonomi barat lalu ditafsirkan dengan konsep Islam. Oleh sebab itu, akan dijelaskan dalam pembahasan ini, dengan melihat problematika yang dihadapi manusia dalam mencapai falah, Umer Chapra menafsirkan bahwa apa yang dilakukan tersebut merupakan suatu perkara yang akan membawa kegagalan yang nyata. Hal ini dikarenakan, bahwa kerangka dari filosofi ekonomi barat dan ekonomi Islam sangat transparan akan perbedaannya. Sehingga penulis mengambil judul Eksplorasi Konsep Falah Perspektif Umer Chapra.

\section{KAJIAN TEORI Konsep Falah dan Hayah Thoyyibah}

Falah berasal dari bahasa Arab dengan kata kerja atau (fi'il amri) aflaha-yuflihu yang artinya kesuksesan, kemenangan, atau kemuliaan. (Sadi, 2021, p. 20) Dalam artian harfiah, falah diartikan sebagai kemenangan atau kemuliaan, yaitu kemenangan atau kemuliaan dalam kehidupan. Dalam Islam, istilah falah diambil dari salah satu kata dalam Al-Qur'an yang dapat dimaknai sebagai keberuntungan yang abadi, yaitu keberntungan dunia dan akhirat, sehingga tidak memandang sesuatu dari aspek material saja melainkan aspek ritual juga. Falah merupakan konsep yang memiliki banyak dimensi dalam konteks dunia. Yaitu berimplikasi pada aspek individual atau yang biasa disebut mikro dan juga kolektif atau makro.(Arif, 2018, p. 25)

Terdapat tiga pengertian falah untuk kehidupan dunia; yaitu 1) Keberlangsungan hidup (baqa'/survival), 2) Bebas dari kemiskinan (Ghana/freedom from want), 3) 
Kehormatan dan kekuatan ('izzah/power and honour). Sementara pengertian falah untuk kehidupan akhirat terdapat tiga pula; yaitu 1) Keberlangsungan hidup yang bersifat abadi 2) Kesejahteraan yang abadi 3) Kemuliaan yang abadi. (Syakur, 2011, p. 4)

Dalam Kamus Lisan Al- 'Arab, kata al-hayah artinya kehidupan dan merupakan lawan dari kata al-maut (mati). (Manzur, n.d., p. 774). Kata al-hayah/hayat dalam alQur'an merupakan bentuk mashdar dari hayiya-yahya-hayatan, megikuti wazan fa'ilayaf'alu-fa'lan, yang artinya "hidup/kehidupan". Kehidupan yan dimaksud disini merupakan kehidupan dunia dan akhirat.(Darmadi, 2018, p. 308)

Sedangkan kata thayyibah berasal dari kata thayyib yang artinya "baik, sehat, lezat, menentramkan, dan paling utama”. Kata thayyibah yang terdapat dalam al-Qur'an banyak yang ditujukan untuk makanan. Seperti salah satu contoh dalam (QS ALBaqarah ayat: 168) yang artinya; "Wahai manusia, makanlah makanan yang halal dan juga thayyib (baik) dari apa yang ada di bumi, dan janganlah kamu mengikuti langkahlangkah dari setan, karena sesungguhnya setan adalah musuh yang nyata bagi kamu sekalian”.(Rachman, 2008, p. 13)

Jadi, maksud dari hayah thoyyibah adalah kehidupan yang baik, kehidupan di dunia ataupun di akhirat kelak. Kata hayah thoyyibah terdapat dalam al-Qur'an (QS. An-Nahl ayat: 97) yang berbunyi: man'amila saliham min zakarin au unsa wa huwa mu'minum fa lanuhyiyannahu hayatn tayyibah, wa lanajziyannahu ajrahum bi' ahsani ma kanu ya'malun. Yang artinya; "Barang siapa yang mengerjakan amal shaleh, baik laki-laki ataupun perempuan dalam keadaan beriman, maka akan kami berikan kepadanya kehidupan yang baik dan akan kami beri balasan kepada mereka dengan pahala yang lebih baik dari apa yang telah mereka lakukan”.

Kata hayah thoyyibah, yang berarti kehidupan yang baik dan suci ditujukan kepada mereka yang senantiasa melakukan perbuatan baik atau amalan yang shaleh. Definisi hayah thoyyibah menurut para ahli tafsir adalah dimaksudkan kehidupan yang suci dengan terciptanya masyarakat yang disertai dengan ketenangan, kesejahteraan, keamanan, kedamaian, persahabatan, kecintaan dan saling membantu satu sama lain.(Shihab, 1989, p. 204)

\section{Negara Sejahtera}

Konsep negara sejahtera atau welfare state yaitu menjelaskan bahwa negara yeng memiliki tanggung jawab besar atas Negara itu sendiri. Yaitu dengan mensejahterakan rakyatnya melalui pelayanan yang baik, bantuan bagi yang membutuhkan, pencegahan dan perlindungan dari masalah-masalah sosial yang terjadi.(Hadiyono, 2020, p. 23)

Definisi Negara sejahtera pernah disampaikan oleh mantan wakil presiden Indonesia Prof. Dr. Budiono, beliau menyampaikan bahwa welfare state memiliki dua definisi. Pertama, sejahtera hanya dalam ruang lingkup masalah ekonomi. Kedua, definisi yang lebih luas karena menganggap sejahtera Negara tidak hanya mencakup ruang lingkup sosial dan ekonomi saja, melainkan juga politik beserta hak-hak sipil bagi warga negaranya. Beliau juga menjelaskan upaya yang harus dilakukan agar welfare state tercapai. Yaitu dengan mengkonsulidasikan beberapa program yang sudah ada agar lebih konsisten lagi antara satu program dengan yang lainnya. Selain upaya 
tersebut, beliau juga menjelaskan upaya yang lain, yaitu dengan mengelompokka beberapa program tadi dalam kelompok yang besar. Kemudian membuat strategi nasional dari masing-masing kelompok di atas.(UMY, 2016)

\section{METODE PENELITIAN}

Peneliti menggunakan jenis penelitian yaitu penelitian pustaka kualitatif, dalam proses penelitiannya didasarkan pada membaca, mempelajari dan menyajikan beberapa referensi, yang berarti membaca bahan-bahan yang berkaitan dengan judul penelitian. Penelitian desktop merupakan upaya untuk mencari hasil dari masalah saat ini dan bacaan yang tersedia, kemudian membaca tentang banyak bahan yang berhubungan langsung dengan judul penelitian. Untuk mendeskripsikan data di lapangan penelitian, peneliti menggunakan metode deskriptif analitis. Dan peneliti tidak menempatkan hasilnya pada metode deteksi saja, tetapi juga pada metode deskriptif analitis.

\section{HASIL PENELITIAN DAN PEMBAHASAN}

\section{Biografi Umar Chapra}

M. Umer Chapra dilahirkan di Pakistan pada tanggal 1 Februari 1933. Ayahanda beliau bernama Abdul Karim Chapra yang mendidik keluarganya dengan penuh ketaatan terhadap agama, sehingga membentuk karakter Umer Chapra menjadi figur yang beretika dan moral yang baik.(Su'aidi, 2012, p. 4) Beliau merupakan ekonom Islam yang memiliki banyak riset dalam bidang ekonomi kontemporer dan menyimpan paham yang baik terkait syariat Islam. Gagasan yang lahir dari hasil pemikiran beliau memiliki nilai visiable dan sangat realistis untuk diaplikasikan kedalam peradaban manusia. Terutama dalam bidang sistem ekonomi serta keuangan modern yang erat korelasinya terhadap konsep kuangan, perbankan, dan kebijakan moneter. Dalam kuasa Umar Chapra, konsep pemikiran ekonomi Islam tidak terbatas pada gagasan yang idealis. Namun, sangat praktis dan fungsional dalam pelaksanaannnya.(Mulyadi, 2019, pp. 80-167)

Dalam bidang pendidikan, M. Umer Chapra melanjutkan pendidikannya pada jenjang magister di Karachi, Pakistan. Kemudian gelar Ph. D diraihnya dalam bidang ekonomi dengan perdikat cumlaude di Universitas Minnesota, Minneapolis, Amerika Serikat. Lalu beliau bergabung dalam komunitas Central Institute of Islamic Research yang berada dikampung halamannya, selama dua tahun. Selama berasosiasi dalam lembaga tersebut, Umer Chapra berhasil melahirkan gagasan serta prinsip-prinsip untuk pondasi dasar dari sistem ekonomi yang sehat. Ide tersebut tertuang dalam bukunya berjudul, The Economic System of Islam: A Discussion of Its Goals and Nature, London-1970. (Mulyadi, 2019, pp. 80-167) Selanjutnnya beliau berhasil menduduki jabatan sebagai ekonom senior dan Associate Editor pada Pakistan Development Review di Pakistan Institute of Economic Development. (Mulyadi, 2019, p. 171)

Umer Chapra menjadi tenaga pengajar dibeberapa perguruan tinggi yang ternama. Diantaranya yaitu Harvard Law School, Universities of Wiscousin, United States, Universitas Autonoma, Madrid, Universitas Loughborough, U.K, Oxford Center for Islamic Studies, London School of Economic, Universitas Malaga, Spanyol, dan beberapa Universitas diberbagai belahan negara lainnya. Umer Chapra juga masuk kedalam asosiasi Saudi Arabian Monetary Agency (SAMA), Riyadh, dengan jabatan sebagai penasihat ekonomi, dan pensiun sampai dengan tahun 1999. Umer Chapra juga menjabat sebagai penasehat riset di Islamic Research and Training Institute (IRTI) di Islamic Development Bank (IDB), Jeddah. Pada tahun 2002-2005, Umer Chapra 
menjabat sebagai komisi teknis pada Islamic Financial Services Board (IFSB) dan sebagai perancang standar industri keuangan Islam. Dari peran dan jasanya yang melahirkan banyak pemikiran dalam dunia ekonomi Islam, the Islamic Development Bank memberikan penghargaan kepada Umer Chapra dalam bidang Ekonomi Islam, dan selain itu, Umer Chapra mendapatkan penghargaan dari King Faisal katagori bidang studi Islam. Selanjutnya pada tahun 1990, Umer Chapra meraih penghargaan dari Presiden Pakistan, berupa medali emas dari IOP (Islamic Overseas of Pakistanis) untuk kontribusinya dalam Islam dan Ekonomi Islam, pada saat konferensi pertama IOP di Islamabad. (Amalia Euis, 2005, pp. 297-298)

\section{Konsep Falah dan Hayyah Thayyibah}

M. Umer Chapra dalam bukunya menjelaskan bahwa setiap manusia merupakan pelaku ekonomi yang pada diri manusia tersebut berpegang pada suatu pandangan (worldview). Sehingga dengan pegangan worldview tersebut, manusia dapat berasumsi terkait alam semesta dan hakikat dasar dari kehidupan umat manusia diatas dunia. Dalam konsep pemikiran Umer Chapra menegaskan bahwa worldview memiliki peran penting dalam menentukan strategi yang dihasilkan dari rasionalitas manusia, sehingga strategi yang diterapkan dapat seimbang dan tepat sasaran serta logis untuk mencapai tujuan yang efektif.(M. Chapra, 1992, p. II)

"......Every society and system is dominated by its own worldview which is based on a set of implicit or explicit assumptions about the origin of the universe and the nature of the human life. It must also have an effective way of bringing about socio-economic restructuring to enable a prompt transfer of resource from one use to another until the most efficient and equitable allocation and distribution have been attained. Unless the worldview and the Strategy of a system are in harmony with its professed goals, the goals cannot be actualised.....'(M. Chapra, 1992, p. II)

Dalam bukunya yang berjudul falah dan hayatan thoyyibatan, Umer Chapra menjelaskan tentang tantangan yang dihadapi oleh negara-negara muslim. Konsep falah dan hayya thayyibh merupakan sarana untuk meraih kebahagiaan dunia maupun akhirat yang merupakan refleksi dari apa yang dilakukan manusia di dunia. Secara tidak langsung hal ini menjadikan sebuah keharusan bagi setiap manusia untuk memperhatikan etika moral yang baik, persaudaraan dan keadilan sosio-ekonomi, lalu upaya pengalokasian sumber daya yang langka untuk menghilangkan masalah kemiskinan dan sebagai sarana dalam pemenuhan kebutuhan, serta menurunkan kesenjangaan atas pendapatan harta benda.

Umer Chapra juga menjelaskan bahwa strategi dari teknik capaian tujuan sirkulasi ekonomi Islam yaitu, adanya kontribusi dalam memanifestasikan kesejahteraan umat manusia dengan pengalokasian distribusi sumber-sumber daya yang langka dengan berlandaskan konsep maqahid syariah. Akan tetapi tidak membatasi kebebasan atas individu, namun mampu menghindari faktor ketidakstabilan makro ekonomi serta eksploitasi secara berlebihan. Karena pada permasalahan tersebut akan membuat solidaritas dan etika moral antar keluarga dengan lingkungan sosial umat manusia menurun.(Anggrianto et al., 2019)

Kajian yang dilakukan oleh Umer Chapra mengenai akibat dari terciptanya kemiskinan dan kesenjangan kehidupan manusia pada setiap negara merupakan akibat dari keputusanan strategi yang diterapkan, ideologi yang bersifat duniawi atau kebendaan (sekuler), faham kapitalisme, sosialisme dan negara kesejahteraan.(Su'aidi, 
2012, pp. 1-8) Namun, hasil yang diharapkan tidak mampu menuntun kehidupan manusia untuk mencapai kebahagiaan. Dengan tegas Chapra menjelaskan bahwa kebahagiaan yang dirasakan manusia dalam kehidupannya haruslah berbanding lurus dengan batinnya. Dalam firman Allah SWT surat al-Fajar ayat 27 yang berbunyi: Ya ayyatuhan-nafsul-mutma "innah yang artinya "Hai jiwa yang tenang".

Lalu Chapra memformulasikan solusi dari permasalahan-permasalahan ekonomi yang menimpa negara-negara Islam, diantaranya yaitu: moral filter dalam mengalokasikan penggunaan sumber daya yang langka, agar membantu efisiensinya, pemanfaat yang sesuai dengan mekanisme filter, serta restrukturisasi aspek sosioekonomi yang akan menjadi pondasi dasar dari bentuk hayyah thayyibah.

\section{Problematika Tujuan Falah Untuk Maslahah}

sejak awal terbentuknya sistem Ekonomi Islam, telah mananamkan pondasi dasar berupa hukum syariat yang mengikat seluruh tatanan kehidupan manusia. Dengan memperhatikan aspek yang dapat direalisasikan, agar tujuan falah dan hayya thayyibah tercapai. Pun akibat dari penjagaan atas keyakinan setiap umat, pemeliharaan jiwa atau kehidupan, akal pikiran, keturunan, serta harta.(M. M. Chapra, 1992, p. 7) Namun, dalam proses mencapai puncak falah, manusia akan menemui banyak perkara, yang timbul dari berbagai faktor dan saling berkaitan satu dengan yang lainnya. Hal ini timbul akibat dari adanya faktor keterbatasan, kekurangan, dan kelemahan pada diri manusia serta ketergantungan dalam berbagai sektor kehidupan, sehingga menghambat manusia untuk meraih falah.(Amirudin, 2015, pp. 62-75)

Dalam konsep pemikiran ekonom konvensional, problem mendasar yang mempengaruhi tingkat kesejahteraan individu adalah adanya kelangkaan dari sumber daya. Sumber daya yang minim tidak dapat menyeimbangi dengan kuantitas keinginan atau kebutuhan dari setiap manusia. Dari faktor kelangkaan sumber daya ini, timbullah istilah yang disebut dengan scarcity. Permasalahan kelangkaan ini tentu dirasakan oleh setiap negara di dunia, baik negara maju dan negara berkembang.(Triono, 2012, p. 164) Sehingga menimbulkan permasalahan kemiskinan, kenaikan harga produk, terjadinya defisit, banyaknya pengangguran, dan lain sebagainya. Namun, dalam dunia ekonomi Islam, konsep kelangkaan dipandang sebagai masalah yang relatif, dimana kelangkaan dari sumber daya ini terjadi dalam waktu yang singkat dan tertentu. Sehingga mengakibat distribusi yang tidak merata, keterbatasan manusia, dan konflik dari tujuan hidup.(Dirwan, n.d.)

Dalam ekonomi Islam, memprioritaskan etika moral dari manusia dan masyaralat yang konsisten dapat mendukung terwujudnya kemaslahatan umat manusia. Dari aspek produksi dan distribusi yang terintegrit pun akan mewujudkan mashlahah bagi umat manusia. Proses produksi yang dilaksanakan dengan efisien dan adil, sehingga mencukupi segala kebutuhan manusia, lalu didukung oleh faktor distribusi yang adil dan merata pada setiap individunya, serta etika konsumsi yang tetap menjaga kepentingan dan kebutuhan antar manusia, akan membantu target dari mashlahah akan tercapai, pun dengan falah, dengan tututan faktor diatas dapat dijalankan dengan sempurna.(Amirudin, 2015) Namun, faktor terpenting yang mendorong orientasi falah atau mashlahah dan hayyah thayyibah adalah kesadaran pada diri manusia itu sendiri.

“........jika manusia menyadari pentingnya falah, maka ia akan selalu berusaha mengelola sumber daya yang ada untuk mencapai falah tersebut....”(U. Chapra, 1985, p. 15) 
Dalam ajaran Islam, manusia di arahkan untuk mempertimbangkan antara etika moral dan kebutuhan manusia terhadap materi. Dengan mengekspresikan keseimbangan dan keadilan sosio ekonomi serta persaudaraan antar manusia. (U. Chapra, 1985, p. 15)

Hal ini memberi gambaran bahwa ajaran Islam rahmatan lil alamin, dan mampu menyelaraskan dengan perubahan dan perkembangan dunia yang tengah terjadi. Namun hal ini tidak luput dari peran pemerintah yang membantu dalam penerapan hukum dan ajaran Islam.(Muhammad, 2004, p. 14) Untuk itu, perkembangan ilmu pengetahuan dan kemajuan teknologi pada zaman sekarang, menutut para ekonom muslim, dan ulama untuk berusaha melakukan kontribusi dan ijtihad dengan modifikasi pengetahuan yang inovatif.

\section{Solusi Kritis Umer Chapra Terhadap Problematika Kesejahteraan}

Rekonseptualisasi yang diformulasikan oleh Umer Chapra melahirkan solusi baru bagi pembangunan ekonomi. Dengan melakukan pemikiran yang realistis dapat menghadirkan sebuah kebahagiaan dan kesejahteraan manusia yang berlandaskan kepada ajaran agama Islam. Umer Chapra berkontribusi dalam menawarkan strategi dari permasalahan ekonomi, diantaranya yaitu, mekanisme filter moral, mengedepankan kepentingan sosial, restrukturisasi sosio-ekonomi, intervensi negara dalam aktivitas ekonomi. Dan menurut Chapra, strategi diatas dapat diaktualisasikan dengan membangunkan jiwa kemanusiaan, menghilangkan fokus terhadap kekayaan, restrukturisasi ekonomi dan keuangan, serta berorientasi untuk mensejahterakan kahidupan manusia.

Menurut Umer Chapra, memprioritaskan perwujudan falah dan kemajuan dalam aspek kehidupan manusia bersumber dari dua faktor utama, yaitu, ekonomi dan moral.(M. M. Chapra, 1992) Dalam firman Allah SWT surat al-Ra'du ayat 11: Lahu mu'aqqibatum mim baini khalfihi yahfazunahu min amrillah, innallaha la yughoyyiru ma biqaumin hatta yugayyiru ma bi anfusihim, wa iza aradallahu biqaumin su'an la maradda lah, wa ma lahum min dunihi miw wal. Yang artinya "Setiap dari manusia terdapat malaikat yang akan selalu mengikutinya secara bergiliran, baik di depan dan di belakangnya, mereka menjaga manusia atas perintah Allah SWT. Sesungguhnya Allah tidak akan merubah keadaan suatu kaum sampai mereka mengubahnya sendiri. Dan apabila Allah menghendaki akan suatu keburukan terhadap suatu kaum, maka taka da seorangpun yang dapat menolaknya; dan tidak aka nada pelindung bagi mereka selain Allah".

Umer Chapra mengelaborasikan terkait aktivitas dalam perekonomian Islam harus memiliki padangan dasar yang menjadi rumusan dari strategi dan tujuan yang akan diraihnya. Pandangan Islam inilah yang membedakan dengan cara pandang manusia ekonomi konvensional. Tiga konsep dasar dari pandangan hidup Islam, yaitu: 1. Tauhid: konsep ini merupakan turunan dari logika yang mengandung kejelasan terkait adanya alam semesta tidak muncul dengan sendirinya, melainkan diciptakan dan dibentuk oleh Allah SWT. Hal ini menjadikan manusia untuk hidup patuh dan beribadah kepada Allah, yang telah diberi akal dan kesadaran moral. Sebagai bentuk pengakuan dan respon yang rasional. 2. Khilafah: konsep khilafah merupakan konsep yang menyatakan bahwa setiap manusia yang dilahirkan mempunyai tanggung jawab terhadap Allah SWT atas segala aktifitasnya selama didunia. Sehingga, prinsip amanah berada dalam tanggungan seorang khilafah dalam mengolah sumber daya, yang harus tetap dijaga dan dimanfaatkan sesuai syariat Islam. 3. A'dalah: konsep ini mencakupi aspek kebutuhan 
pokok manusia. Konsep ini bertujuan untuk menghindari terjadinya kesenjangan ekonomi yang akan memberikan dampak kepada degrasi pemenuhan kebutuhan orang lain. Ajaran Islam yang menegaskan untuk memperkuatkan persaudaraan dan keadilan agar segala sumber daya yang diciptakan-Nya dapat dimanfaatkan dengan sebaikbaiknya, yang merupakan amanat suci dari Allah SWT, guna mengaktualisasikan tujuan dari maqashid.

Sumber daya yang diciptakan oleh Allah SWT dalam dunia ini tidak terjangkau. Sehingga mampu mencukupi kebutuhan dan mencapai kesejahteraan makhluk hidup diatas dunia. Namun, permasalahan yang sesungguhnya terletak pada sistem pemanfaatan dari sumber daya itu sendiri. Apakah merata dan efisien untuk memenuhi kesejahteraan (falah) manusia. Dan kesejahteraan (falah) akan tercapai apabila sistem pengelolaannya berdasarkan dengan rasa tanggung jawab dan batasan yang sesuai dengan ketetapan dan arahan dari Ilahi dan maqashidnya.(M. M. Chapra, 1992, p. 203) Konsep Khilafah ini, dalam bukunya Islam and Economic Challenge Umer Chapra menjelaskan sejumlah implikasi dari konsep ini, diantaranya adalah: 1) Persaudaraan Universal, konsep ini mengarahkan manusia untuk tidak hanya melayani kepentingan diri sendiri, melainkan saling membantu dalam memenuhi kebutuhan dasar, dengan mengandal pontensi yang ada agar manusia sampai pada konsep sejahterah. 2) Sumber daya adalah kepercayaan, sumber daya yang dimanfaatkan manusia merupakan bentuk pemberian Allah SWT untuk memenuhi semua kebutuhan manusia, bukan hanya sebagian. Setiap individu manusia harus mengolah sumber daya dengan tepat, dengan menjadikan Al-Qur'an dan Sunnah sebagai benteng agar terhindar dari pelanggaran perintah-Nya. Tidak menjadi egois, serakah dan tidak beretika moral yang bekerja hanya untuk mencapai kesejahteraan pribadi. Dan tidak seorang pun dari manusia untuk merusak sumber daya yang telah Allah SWT sediakan. 3) Gaya Hidup Rendah Hati. 4) Kebebasan manusia, dalam konsep ini, manusia bebas dalam melakukan apapun yang mereka inginkan, namun, dengan ketentuan harus tunduk kepada syariat Islam.

Selain itu, Umer Chapra memberikan strategi yang didalamnya terdapat empat elemen yang dapat memperkuat keseluruhan sistem ekonomi, yaitu: 1) Mekanisme moral filter yang diterima oleh social. Mekanisme ini membantu dalam menyeimbangkan moral dalam memfungsikan sumber daya untuk fungsi kesejahteraan manusia dan tidak membiarkan pemanfaatan kearah yang dilarang secara moral. Contohnya, membahayakan keselamatan manusia, hewan atau tumbuh tumbuhan akibat eksploitasi yang berlebihan. Dengan hal ini, gaya hidup yang rendah hati serta tidak boros merupakan faktor dalam meraih falah tersebut. 2) Motivasi untuk berbuak baik terhadap diri sendiri dan masyarakat. Rasionalitas dalam tahap konsep ini adalah sumber daya yang dikonsumsi dapat menjaga kesejahteraan dalam jangka panjang, dan juga hemat dengan peningkatan produksi dan distribusi barang-barang yang membantu dalam pemenuhan kebutuhan dasar dalam melayani kepentingan masyarakat miskin. 3) Restrukturisasi sosio-ekonomi dengan tujuan mewujudkan dari hukum maqashid syari'ah. Menurut Umer Chapra, dimensi sosial dan ekonomi dalam restrukturisasi dapat dilakukan dengan memperkuat segi reformasi politik. Dalam hal ini, restrukturiasi harus memiliki tujuan yang dituju, diantaranya adalah: memotivasikan setiap individu untuk melaksanakan tugas mereka dengan tujuan mewujudkan efisiensi dan kesetaraan, mengurangi konsentrasi terhadap kekayaan, memperkuat sistem ekonomi dan politik yang adil, reformasi seluruh lembaga sosial, termasuk keuangan publik dan intermediasi keuangan. Dapat disimpulkan bahwa dalam tahap ini dibutuhkan reformasi dalam diri manusia serta restrukturisasi secara keseluruhan dari pola konsumsi dan investasi. 
Hakikat dari suatu institusi yang diulas dalam buku Umer Chapra adalah dalam restrukturisasi sosio-ekonomi menjadikan Al-Qur'an dan Sunnah sebagai literatur utama. Sehingga, Umer Chapra menegaskan bahwa, empat faktor yang perlu diperhatikan dengan khusus dalam konsep restruktirisasi ini yaitu, penggunaan sumber kepercayaan secara hati-hati, swadaya sosial melalui pembayaran zakat dan sedekah lainnya, warisan dan reorganisasi sistem keuangan. Dengan perumusan penetapan kebijakan ini, maka mampu mewujudkan maqashid akan jelas. 4) Intervensi pemerintah yang positif dan kuat. Dalam realisasi restrukturisasi ini akan terwujudkan dengan keterlibatan pemerintahan negara dalam aspek perekonomian. Peran negara dalam ranah perekonomian merupakan peranan yang menempatkan tempat yang paling penting dalam politik Islam sejak awal hingga saat ini.

\section{PENUTUP}

Berdasarkan dari pemaparan diatas, permasalahan dari kesejahteraan manusia adalah moralitas manusia itu sendiri. Moral yang menuntun manusia untuk berinteraksi dengan rasional terhadap sumber daya yang ada sampai dengan aktivitas ekonominya. Untuk itu, ekonomi Islam merupakan strategi yang diformulasikan antara ilmu ekonomi dan moral masyarakat yang tidak menganut faham individualisme yang tinggi. Nilai-nilai yang terkandung dalam Al-qur'an dan sunnah menjadi konsep pokok fundamental yang bertujuan untuk menciptakan kesejahteraan seluruh umat manusia. M. Umar Chapra merupakan pemikir ekonomi Islam, telah banyak berkontribusi dalam menawarkan strategi-strategi untuk mancapai tujuan ekonomi Islam. Seperti sistem mekanisme filter pada moral, yang bertujuan untuk mengutamakan kepentingan sosial, sebab moral yang baik akan melahirkan keadilan sosio-ekonomi, dan menjadi pembeda antara ekonomi Islam dan barat. Dalam restrukturisasi sosio-ekonomi, intervensi pemerintah mempunyai peran penting dalam menguatkan sistem dan komplementer ekonomi. Untuk merealisasikan diatas, Umer Chapra pun memberikan kebijakan bahwa dalam penyeselesai dari problem kesejahteraan adalah, menghidupkan jiwa kemanusiaan, menghilangkan konsistasi kekayaan, melakukan restrukturisasi sosio-ekonomi dan keuangan, serta menyusun strategi yang berorientasi kearah mensejahterakan segala bentuk lini kehidupan umat manusia.Saran dari hasil penelitian di atas adalah: 1. Bagi masyarakat, untuk dapat mendidik diri dan jiwa pribadi mereka, terutama pada anakanak mereka agar menanamkan nilai-nilai kehiudpan uang Islami dengan berpedoman pada Al-Qur'an dan Sunnah. Penanaman nilai dan pendidikan terkait makna hakiki terhadap konsep definisi kesejahteraan, kedamaian, kesusksesan dan kebahagiaan dalam Islam. 2. Bagi pemerintah, untuk terus mengevaluasikan, memikirkan, dan menjalankan tugas dengan amanah. Guna apa yang diperjuangkan dapat mewujudkan kesejahteraan

bagi kehidupan masyarakat bernegara, baik dari segi materi dan spiritual. 3. Bagi perguruan tinggi, agar tenaga para pendidik untuk tetap terus berpegang teguh mempertahankan dan berusaha memahami nilai-nilai epistemology dari falah, sehingga para mahawasiswa dapat memiliki prinsip dari definisi konsep falah yang benar. Dan keluar dengan lulusan yang mampu berkiprah ditengah masyarakat dengan memperbaiki kekeliruan akan nilai dan pemahaman dari konsep falah.

\section{DAFTAR RUJUKAN}

Amirudin, K. (2015). Nilai Maslahat Dalam Sistem Ekonomi Islam. EcceS: Economics, Social, and Development Studies, 2(1), 62-75. 
Anggrianto, L., Studi, P., \& Islam, E. (2019). Konsep Keadilan Dalam Teori Pareto Optimum.

Arif, M. (2018). Filsafat Ekonomi Islam. UINSU Press.

Chapra, M. M. (1992). Islam and The Economic Challenge. In Review of Islamic Economics (Vol. 2, Issue 1).

Chapra, U. (1985). Towards a Just Monetery System, . Islamic Foundation.

Darmadi. (2018). Konservasi Sumber Daya Manusia dalam Ekosistem Pendidikan Islam. JSI Press.

Dirwan. (n.d.). kelangkaan Teori Nilai dan Teori harga Dalam Perspektif Ekonomi Islam (Kritik Terhadap Politik Kapitalisme).

Hadiyono. (2020). Indonesia dalam Menjawab Konsep Negara Welfare State dan Tantangannya. Jurnal Hkum Politik Dan Kekuasaan, 1.

Manzur, I. (n.d.). Lisan Al-'Arab.

Muhammad. (2004). Ekonomi Mikro Dalam Perspektif Islam. yogyakarta, BPPE.

Mulyadi, D. (2019). PEMIKIRAN EKONOMI ISLAM UMER CHAPRA (Studi Analisi Terhadap Sistem Ekonomi Kapitalisme, Sosialisme, dan Negara Sejahtera). ADLIYA: Jurnal Hukum Dan Kemanusiaan, 10(2), 167-180. https://doi.org/10.15575/adliya.v10i2.5153

Rachman, F. (2008). 8 Kalimat Al-Thayyibah Ringan di Lisan, Berat di Timbangan Amal. Penerbit Mizania.

Sadi, S. H. \& M. (2021). Hukum Zakat dan Wakaf di Indonesia. Kencana.

Shihab, Q. (1989). No Title.

Su'aidi, M. Z. (2012). Pemikiran M. Umer Chapra tentang Masa Depan Ekonomi Islam. Ishraqi, 10(1), 1-19.

Syakur, A. (2011). Dasar-Dasar Pemikiran Ekonomi Islam. STAIN Kediri Press.

Triono, D. C. (2012). Ekonomi Islam Mazhab Hamfara.

UMY, T. H. of. (2016). Masyarakat Indonesia Perlu Pahami Kembali Konsep Negara Sejahtera. Universitas Muhammadiyah Yogyakarta. https://www.umy.ac.id/masyarakat-indonesia-perlu-pahami-kembali-konsep negara-sejahtera 